\title{
A Simple Angle-Resolved Thermal Molecular Beam Reactor: Applied to CO Oxidation on Pt\{110\}
}

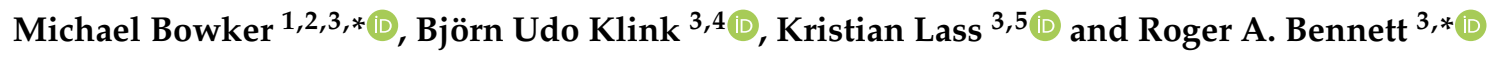 \\ 1 Cardiff Catalysis Institute, School of Chemistry, Cardiff University, Cardiff CF10 3AT, UK \\ 2 Catalysis Hub, RCAH, Rutherford Appleton Laboratory, Harwell, Oxfordshire OX11 0FA, UK \\ 3 Department of Chemistry, University of Reading, Reading RG6 6DX, UK; \\ Bjoern.klink@mpi-dortmund.mpg.de (B.U.K.); Kristian.Dr.Lass@polizei.landsh.de (K.L.) \\ 4 Department of Structural Biochemistry, Max Planck Institute of Molecular Physiology, Otto-Hahn-Str. 11, \\ 44227 Dortmund, Germany \\ 5 Forensic Scientific Institute, State Criminal Police Office of Schleswig-Holstein, 24146 Kiel, Germany \\ * Correspondence: bowkerm@cf.ac.uk (M.B.); r.a.bennett@reading.ac.uk (R.A.B.); \\ Tel.: +44-(0)29-2087-0120 (M.B.)
}

Received: 23 September 2020; Accepted: 21 October 2020; Published: 23 October 2020

\begin{abstract}
We developed a simple form of thermal molecular beam catalytic reactor system which is capable of measuring sticking probabilities and reaction probabilities, together with angle-resolved scattering of molecules and products during catalytic reactions at the surface. This includes very fast determination of the angle dependence of the reaction product flux at steady-state. It was employed to determine the oxidation of $\mathrm{CO}$ on $\mathrm{Pt}\{110\}-(1 \times 2)$, including individual molecular sticking and scattering. The initial sticking probability of oxygen on $\mathrm{Pt}\{110\}$ shows a small variation between 140 and $750 \mathrm{~K}$ surface temperature, from 0.45 to 0.28 . The saturation uptake drops from $1.5 \pm 0.2 \mathrm{ML}$ at $140 \mathrm{~K}$ to $0.6 \mathrm{ML}$ at $300 \mathrm{~K}$ and to $0.23 \pm 0.02 \mathrm{ML}$ at $750 \mathrm{~K}$. The initial sticking probability of CO at $300 \mathrm{~K}$ is 0.80 and decreases to 0.62 at $470 \mathrm{~K}$. Beyond that temperature, it descends steeply down to near zero at $570 \mathrm{~K}$, due to the high desorption rate of $\mathrm{CO}$ at that temperature. Kisliuk precursor mobility parameters $\mathrm{K}$ were calculated from shape of the sticking curves. For $300 \mathrm{~K}$, a value of $0.11 \pm 0.01$ was found, which increases to $0.76 \pm 0.01$ at $470 \mathrm{~K}$, indicating a change from considerable mobility in the precursor state, to more limited mobility before desorption at high temperature. In temperature-programmed $\mathrm{CO}-\mathrm{O}_{2}$ reaction experiments, $\mathrm{CO}_{2}$ production was observed to initiate in the temperature region $460-510 \mathrm{~K}$. Using isothermal angle-resolved experiments, the $\mathrm{CO}_{2}$ flux was determined in the $[1 \overline{1} 0]$ plane at temperatures of 470-620 K. Two sharp scattering lobes at positions of $\pm 16^{\circ}$ off the surface normal were found, with a high cosine power angle dependence, which were attributed to desorption from the $\{111\}$-like microfacets of the $1 \times 2$ reconstructed surface, with products evolving over a high barrier.
\end{abstract}

Keywords: platinum; carbon monoxide; oxidation; catalysis; molecular beam; temperature programmed desorption; surface science

\section{Introduction}

Molecular beam methods are important means of analyzing the surface reactivity and structure of single crystal surfaces. By using a molecular beam to supply the crystal continuously with new reaction mixture, it is possible to measure reactions under steady-state conditions, which is not possible by ARTPD (angle-resolved temperature programmed desorption), since, due to the temperature ramping, it is essentially a non-steady-state kind of experiment. Recent, elegant work on $\mathrm{CO}$ oxidation on $\mathrm{Pt}\{111\}$ for example has shown two channels for reaction, on terrace and step edges, 
which may be distinguished by the desorption characteristics of $\mathrm{CO}_{2}$ [1]. In this paper, we report data for the adsorption, desorption and reaction of $\mathrm{CO}$ and oxygen on the $\{110\}$ surface of platinum using a new design of a molecular beam apparatus. The $\mathrm{CO}$ oxidation was measured in angle-resolved mode under steady-state conditions.

The reconstructed clean $\mathrm{Pt}\{110\}-(1 \times 2)$ surface has a missing-row type structure [2-4]. The Pt atoms build close-packed rows along the $[1 \overline{1} 0]$ direction with every second row missing. Due to these missing rows, there is a series of troughs between the close packed rows. The walls of the troughs can be described as $\{111\}$ microfacets.

Adsorption of $\mathrm{CO}$ is known to lift the reconstruction of the missing-row structure. Above an exposure of $1 \mathrm{~L}$, single $\mathrm{Pt}$ atoms of the first layer diffuse out of the [11 0$]$ atomic rows and occupy lattice sites being out of phase with regard to the $(1 \times 2)$ periodicity [5]. This happens even at temperatures as low as $250 \mathrm{~K}$ [6]. The lifting of the reconstruction leads to a $(1 \times 1)$ low energy electron diffraction (LEED) pattern at CO coverages of about 0.6 ML [7]. This is not due to a bulk-truncated structure but because of a random distribution of top layer Pt atoms on the bulk layer underneath which has a $(1 \times 1)$ periodicity [8]. Oertzen et al. mentioned that the phase transition starts at a CO coverage of $0.2 \mathrm{ML}$ and is completed at $0.5 \mathrm{ML}$ [9]. At $300 \mathrm{~K}, \mathrm{CO}$ adsorbs exclusively at on-top sites up to a coverage of $0.5 \mathrm{ML}$. Above this coverage, a small amount of $\mathrm{CO}$ also adsorbs on bridge sites [10]. The room-temperature saturation coverage of $\mathrm{CO}$ is $0.88 \mathrm{ML}\left(1 \mathrm{ML}=9.22 \times 10^{14}\right.$ molecules $\left.\mathrm{cm}^{-2}\right)$ [11].

In contrast, the adsorption of $\mathrm{O}_{2}$ does not lift the $\mathrm{Pt}\{110\}-(1 \times 2)$ missing-row structure [12]. Performing quantitative X-ray photoelectron spectroscopy (XPS) and work function studies, Freyer et al. found a saturation coverage for room temperature adsorption onto the $(1 \times 2)$ reconstructed surface of $0.35 \mathrm{ML}$ [7]. This value is quite low in comparison to other authors. Walker et al. measured a saturation coverage of close to $1 \mathrm{ML}$ for room temperature adsorption [13]. Below $0.25 \mathrm{ML}$, oxygen is adsorbed in a state where it fluctuates across ridge bridge sites. Between 0.25 and $0.5 \mathrm{ML}$, oxygen is pinned at fcc sites on the walls of the $\{111\}$ microfacets. Due to lateral interactions, only every other site along the row can be occupied at these coverages. As shown by Walker et al., above $0.5 \mathrm{ML}$, oxygen produces a coverage-dependent variable unit mesh structure [13], and this results in a change from second- to first-order behavior for the oxygen desorption above this coverage.

The activation energy for diffusion of $\mathrm{CO}$ on a $\mathrm{Pt}\{110\}-(1 \times 2)$ surface was measured by Oertzen et al. to be about $9-13 \mathrm{kcal} / \mathrm{mol}$, while the activation energy of diffusion for $\mathrm{O}_{2}$ is $30 \mathrm{kcal} / \mathrm{mol}$ for low coverages and $40 \mathrm{kcal} / \mathrm{mol}$ for high coverages [9]. This means that the diffusion of $\mathrm{O}_{2}$ is negligible in comparison to the $\mathrm{CO}$ diffusion. The $\mathrm{CO}$ oxidation will therefore take place nearly exclusively on the surface sites that are occupied by oxygen, with $\mathrm{CO}$ diffusing to these sites for reaction. Oertzen et al. also found a great anisotropy for $\mathrm{O}_{2}$ diffusion, with diffusion occurring only parallel to the crystallographic $\left[1 \frac{1}{10}\right]$ direction. This is consistent with the observation that $\mathrm{O}_{2}$ forms rows in the troughs of the Pt $\{110\}-(1 \times 2)$ surface [9].

Using an ultrathin $\mathrm{Pt}\{110\}$ single crystal, Wartnaby et al. measured the excess energy of desorbing $\mathrm{CO}_{2}$ molecules in comparison to thermally accommodated molecules [14]. They found that, when $\mathrm{CO}$ is dosed onto a saturated oxygen overlayer, the excess energy is $9 \pm 17 \mathrm{~kJ} / \mathrm{mol}$, while the excess energy was $52 \pm 21 \mathrm{~kJ} / \mathrm{mol}$ for oxygen dosed onto a CO overlayer. They explained this behavior by a drop of the reaction activation energy with increasing oxygen coverage and the formation of "hot" oxygen atoms. The "hot" oxygen atoms could react with $\mathrm{CO}$ before thermal accommodation to the surface and therefore carry their excess energy over to the product $\mathrm{CO}_{2}$.

The reaction mechanism of the $\mathrm{CO}$ oxidation reaction was found to be mainly of Langmuir-Hinshelwood type on Pt surfaces, excluding any reaction via the direct collision of gas phase $\mathrm{CO}$ with oxygen adatoms $[15,16]$. On the other hand, Bonzel and $\mathrm{Ku}$ predicted that the reaction on a $\mathrm{Pt}\{110\}-(1 \times 2)$ surface takes place via a Langmuir-Hinshelwood mechanism at conditions where $\mathrm{CO}$ was pre-adsorbed on the surface while with $\mathrm{O}_{2}$ pre-adsorbed on the surface, it shifts to an Eley-Rideal mechanism [17]. 
Using a cross-correlation time-of-flight method combined with non-steady-state angle-resolved thermal desorption (ARTPD), Matsushima et al. measured the angular and velocity distributions of $\mathrm{CO}_{2}$ desorbing from a $\mathrm{Pt}\{110\}-(1 \times 2)$ surface [18-20]. They found that the $\mathrm{CO}_{2}$ desorption is collimated at angles of $\pm 25^{\circ}$ off the surface normal. At these angles, the translational temperature of desorbing $\mathrm{CO}_{2}$ also reaches a maximum. The difference between the facet angles of the $\{111\}$ facet normals of about $\pm 35.2^{\circ}$, and the measured values have been explained by the "smoothing effect" of conducting electrons and surface distortions, the latter reducing the facet angle to about $\pm 30^{\circ}$ as found by LEED and TOF-SARS (time of flight scattering and recoiling spectrometry) investigations [21,22].

Relatively few angle-resolved measurements under steady-state conditions have been performed on the $\mathrm{CO}$ oxidation reaction on Pt surfaces. Cao et al. performed such an investigation on a $\mathrm{Pt}\{113\}$ surface, finding two desorption peaks at angles of $-20 \pm 2^{\circ}$ and at $+22 \pm 2^{\circ}$ off the surface normal [23]. They assigned these results to reactions to the $\{001\}$ and the $\{111\}$ facets of this surface, with facet normals of $-25.2^{\circ}$ and $+29.5^{\circ}$, respectively. On $\mathrm{Pt}\{110\}-(1 \times 2), \mathrm{CO}_{2}$ formation dynamics was probed with angular and velocity resolution at relatively high $\mathrm{O}_{2}$ pressures of $1 \times 10^{-7}-1 \times 10^{-4}$ Torr and found that reactions are dominated by the $(1 \times 2)$ regions of the surface giving hyperthermal desorption directed at $25^{\circ}$ from the surface normal [24]. These were attributed to reactions occurring on the facets.

There has been a great deal of work on the kinetics, light-off and the spatiotemporal oscillations of CO oxidation [25-30] including Ertl's Nobel Prize-winning work [31,32], and the work described above [18-20]. To the best of our knowledge, there have been no continuous angle-resolved measurements under steady-state conditions combining the advantages of molecular beams to access sticking, trapping, uptake and desorption in the $\mathrm{CO}$ oxidation reaction on a $\mathrm{Pt}\{110\}-(1 \times 2)$ surface. Mullins et al. did this for the reaction at $90 \mathrm{~K}$ surface temperature on $\mathrm{Pt}\{111\}$ and found a $\cos ^{12}$ dependence of the scattered flux. However, they used non-thermal and separate sources of $\mathrm{O}_{2}$ (from a microwave source) and supersonic CO [33]. Similarly, in the ground-breaking work of Neugebohren et al., discussed below, high source pressure beams were used [1]. Near ambient pressure XPS experiments have shown how local structure and oxide formation on $\mathrm{Pt}\{110\}$ influence $\mathrm{CO}$ oxidation and provide motivation to continue to develop in-situ tools to probe catalytic reactivity in response to surface nanostructural changes [34].

The aim of this study was to gain a further understanding of the oxidation of $\mathrm{CO}$ on a $\mathrm{Pt}\{110\}-(1 \times 2)$ surface, with continuous thermal beams. By performing the experiments under steady-state conditions, we were able to observe the reaction at much higher temperatures than possible with ARTPD. We used a recently-designed molecular beam machine that can perform fast angle-resolved measurements even in steady-state mode in a continuous manner.

\section{Results and Discussion}

\subsection{Inert Gas Scattering}

To investigate the scattering behavior of $\mathrm{Pt}\{110\}-(1 \times 2)$, experiments with helium and argon were carried out. The results are shown in Figure 1. For helium, an intense sharp peak was observed at an angle of $101 \pm 3^{\circ}$ and a small peak at $37 \pm 3^{\circ}$ (the beam enters the chamber at $45^{\circ}$ and the angle-resolved MS is at $90^{\circ}$ ). In contrast, the scattering curve for argon shows a rather broad and featureless distribution, although the signal maximum is also positioned at around $101^{\circ}$. A specularly reflected He beam from a flat $\mathrm{Pd}\{111\}$ surface shows a sharp maximum at $67.5^{\circ}$ (see Figure S2). For a sample with facets a specularly reflected beam should arise when the facet normal is held at $67.5^{\circ}$ and thus specular peaks are expected at \pm the facet angle which is $\pm 35^{\circ}$ for $\{111\}$ micro facets on $\{110\}$ yielding peaks expected at 32.5 and $102.5^{\circ}$ in our geometry. The experimentally measured angles suggest the facets are slightly less steep than $\pm 35^{\circ}$. 


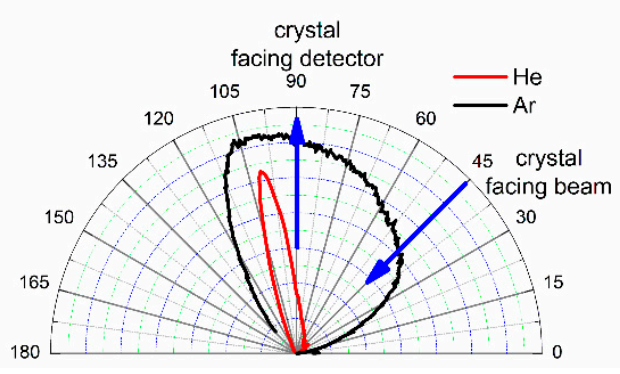

(a)

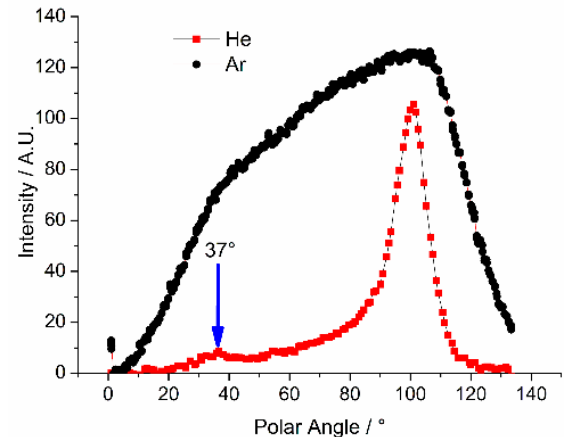

(b)

Figure 1. (a) Polar representation of the scattering of He and Ar from $\mathrm{Pt}(110)$, clearly showing the differences between the light and heavy inert gases. The latter has a much longer residence time on the surface and so becomes largely thermalized to the surface temperature. (b) The signal intensity is plotted as a function of crystal polar angle (Cartesian plot).

For comparison with the experiment, we simulated the scattering at the surface. The $\operatorname{Pt}\{110\}-(1 \times 2)$ surface was modeled by assuming a cosine-shaped hard surface potential (Figure 2). The size of the scattered atoms has been neglected, and only fully elastic scattering has been assumed ("billiard ball model"). Double scattering on both facets was considered and was of minor influence in the idealized simulation. As the facet angle deviates from the geometrical value of $35.2^{\circ}$ for an undistorted surface, an angle of $30^{\circ}$ was used, as this value was reported from LEED [21] and TOF-SARS experiments [22]. The angle between incident beam and detector was set to $45^{\circ}$, with a detector acceptance angle of $\pm 5^{\circ}$. The result of the simulation is shown in Figure 2. It exhibits two sharp peaks at angles of $40^{\circ}$ and $95^{\circ}$.

For helium, the simulation fits the experimental result quite well except for the lack of intensity of the peak at $37^{\circ}$. The reason for this lies in shadowing effect of the facets in a non-ideal surface which is underestimated in the simulation due to the assumption of dimensionless atoms and a hard surface potential (facet bunches due to local miscuts can shadow the outgoing atoms). Each facet also receives a different proportion of the flux so at $\sim 102^{\circ}$ the facet oriented for specular reflection sees the vast majority of the flux, whereas the other facet is at grazing incidence and hence this orientation generates a large signal. At $37^{\circ}$, the beam is at near normal incidence and both facets see similar fluxes so only approximately half of the beam hits the facet aligned for specular reflection, resulting in a smaller signal.

There is some decrease in the transmission function of the system, particularly at high angles where the beam grazes the crystal surface (the mass spectrometer apertures are designed to accept scattered gas from the full width of the sample, but at grazing some beam spill over from the sample edges). Otherwise, the well-reproduced Helium peak positions indicate that the assumed model is adequate for the performed scattering experiment.

In contrast to the simulated scattering, the experimental result for Argon shows no separated peaks, and is due to the fact that Ar scattering is not elastic due to its higher accommodation and a much higher enthalpy of physisorption ( 1-2 kJ/mol for He and about 10× that figure for Ar [35]). A more detailed discussion of these data and fitting of the Ar data is given in the Supplementary Materials. 


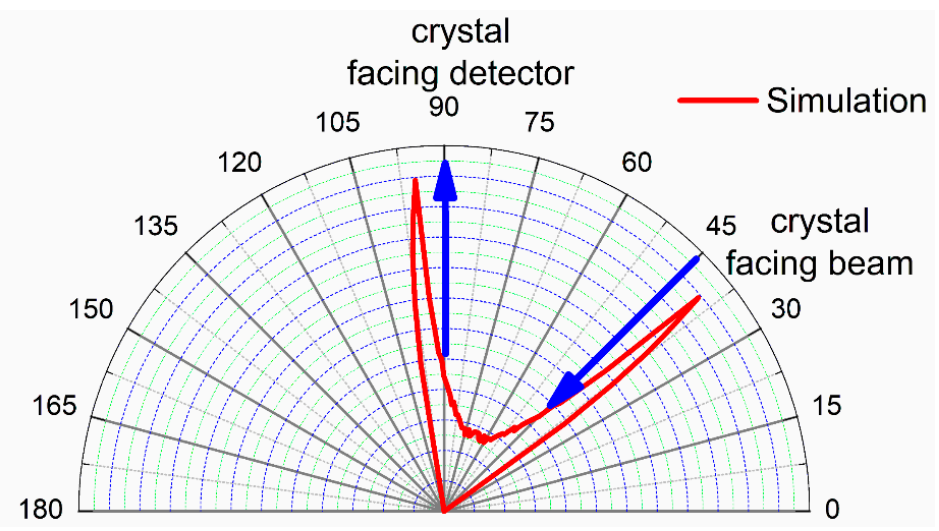

a)
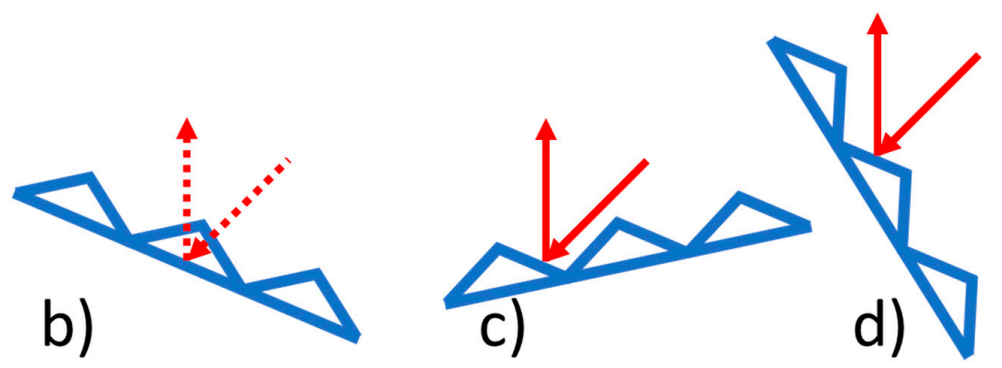

Figure 2. (a) Simulated signal intensity of a scattering simulation for $\mathrm{Pt}\{110\}-(1 \times 2)$. Pictograms of the $\{110\}$ crystal orientation at key specular positions: (b) pseudo-specular reflection from the surface plane ignoring microfacets; (c) specular reflection from first facet $\sim 102^{\circ}$; and (d) specular reflection from second facet at $\sim 33^{\circ}$.

\subsection{Oxygen Interaction with Pt $\{110\}$}

The results for the sticking experiments with oxygen are shown in Figure 3.

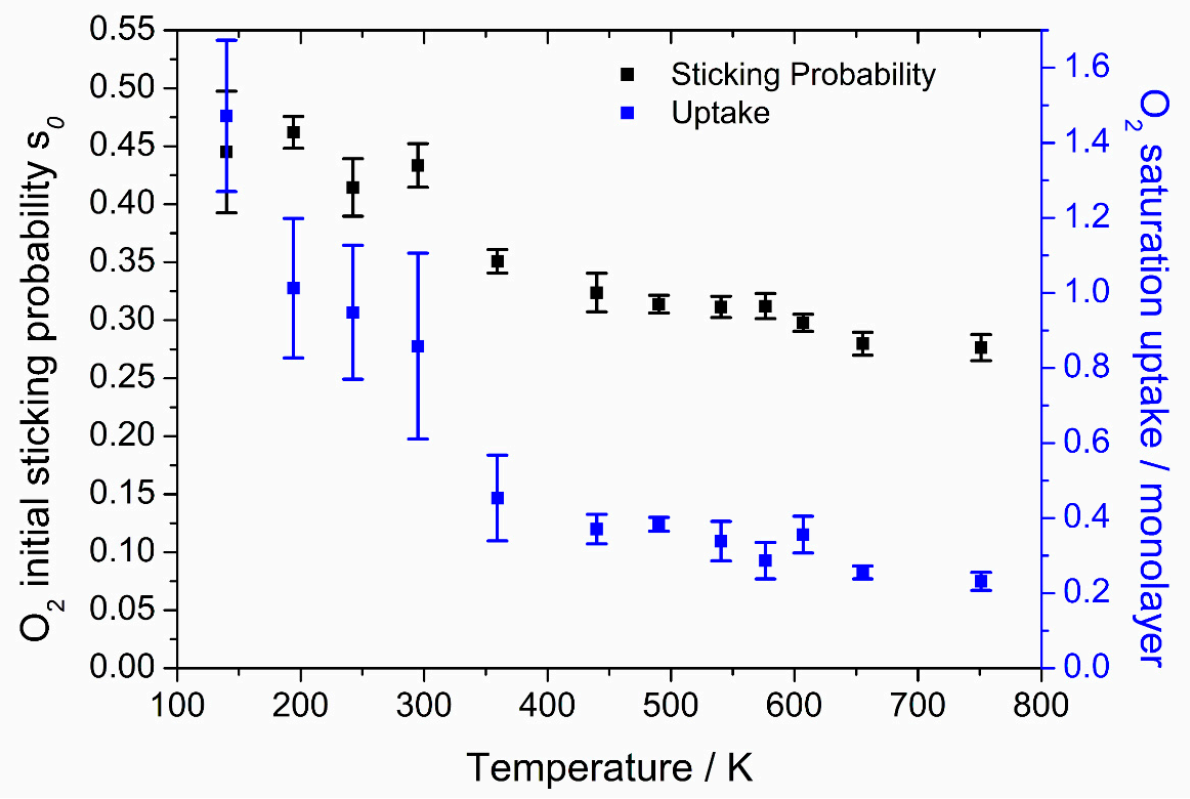

Figure 3. Initial sticking probability of oxygen and saturation coverage (in atoms), as a function of crystal temperature. 
The initial sticking probability $s_{0}$ shows a gradual decrease with increasing surface temperature above $400 \mathrm{~K}$, from 0.34 to 0.27 at $750 \mathrm{~K}$. At lower temperatures, there is a larger decrease from $\sim 0.45$ at $130 \mathrm{~K}$ to 0.36 at $350 \mathrm{~K}$.

The high uptake at low temperatures, and big decrease up to $350 \mathrm{~K}$, coincides with a low-temperature oxygen desorption peak found by Wilf and Dawson at a temperature of $250 \mathrm{~K}$ that extends to $350 \mathrm{~K}$ [12]. A similar observation was made by Walker et al. [13], although they also found a very sharp peak at approximately $220 \mathrm{~K}$. They attributed this peak to the presence of molecularly chemisorbed oxygen $\mathrm{O}_{2}$. Sticking probability versus uptake curves at several temperatures are given in the Supplementary Materials (Figure S3).

The TPD spectra of oxygen are extremely sensitive to the surface structure of a $\operatorname{Pt}\{110\}$ surface. Even a different cooling rate of the crystal after the usual annealing at $970 \mathrm{~K}$ results in significantly altered spectra, possibly due to a change in the step density [22]. $\mathrm{O}_{2}$ TPD is therefore a good test for the quality of the surface structure.

Desorption traces for oxygen TPD as a function of heating rate and coverage are shown in Figures 4 and 5 , respectively. For heating rate dependent TPD (Figure 4), the crystal was dosed with $22.5 \mathrm{~L}$ $\left(3 \times 10^{-5}\right.$ mbar.s $)$ of oxygen at $420 \mathrm{~K}$.

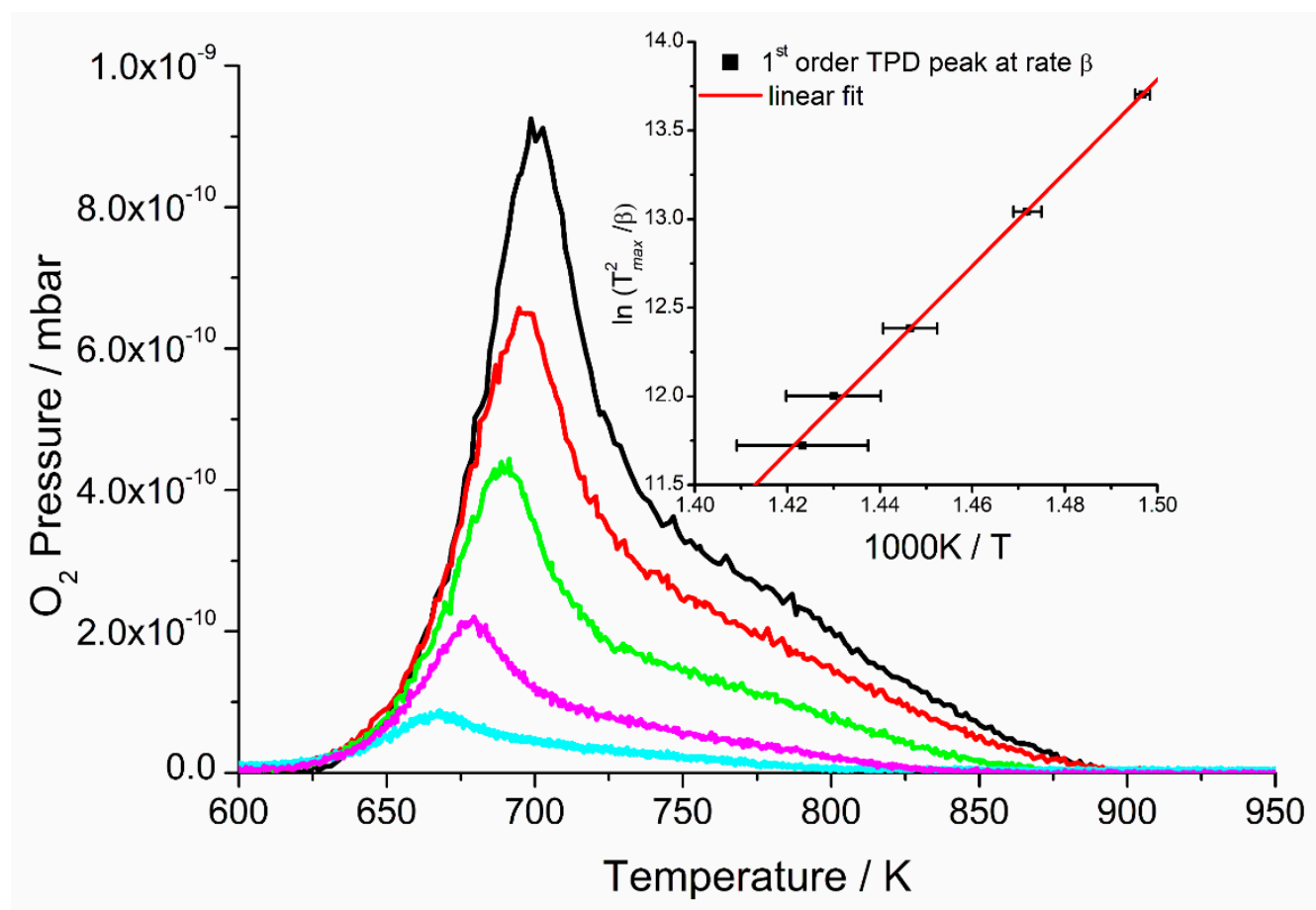

Figure 4. TPD spectra of oxygen for heating rates of $0.5,1,2,3$ and $4 \mathrm{~K} / \mathrm{s}$ in the order of increasing peak maximum. The clean $\mathrm{Pt}\{110\}$ sample was dosed with $22.5 \mathrm{~L}$ of oxygen at $420 \mathrm{~K}$ with TPD recorded angle integrated from the main chamber MS. The insert shows a plot of the peak maximum points linearised according to Equation (1).

The relationship between the peak maximum temperature $T_{\max }$ and the heating rate $\beta$ for a first-order desorption is described by the following equation [12]:

$$
\ln \left(\frac{T_{\max }^{2}}{\beta}\right)=\ln \left(\frac{E_{d}}{v_{1} R}\right)+\frac{E_{d}}{R T_{\max }}
$$

where $v_{1}$ is the preexponential factor of desorption, $E_{d}$ is the desorption energy and $R$ is the molar gas constant. Using this approach, we calculated a desorption energy of $E_{d}=218.6 \pm 5.7 \mathrm{~kJ} / \mathrm{mol}$ and a preexponential factor of $v_{1}=3.6 \times 10^{15 \pm 0.4} \mathrm{~s}^{-1}$. These values are high in comparison to literature. 
Wilf and Dawson found a desorption energy for the $\beta_{1}$ state of $134 \mathrm{~kJ} / \mathrm{mol}$, with a preexponential factor of $1.7 \times 10^{9} \mathrm{~s}^{-1}$ [12], while Walker et al. measured the adsorption heat of $\mathrm{O}_{2}$ using microcalorimetry [13] and found a value of $170 \mathrm{~kJ} / \mathrm{mol}$ for the $\beta_{1}$ oxygen state. They also calculated the desorption energy using the Redhead formula [36] (Equation (2)):

$$
E_{d}=R T_{\max }\left(\ln \left(\frac{v_{1} T_{\max }}{\beta}\right)-3.64\right)
$$

They assumed a preexponential factor of $v_{1}=1 \times 10^{13} \mathrm{~s}^{-1}$ and found a value of $E_{d}=198 \mathrm{~kJ} / \mathrm{mol}$.

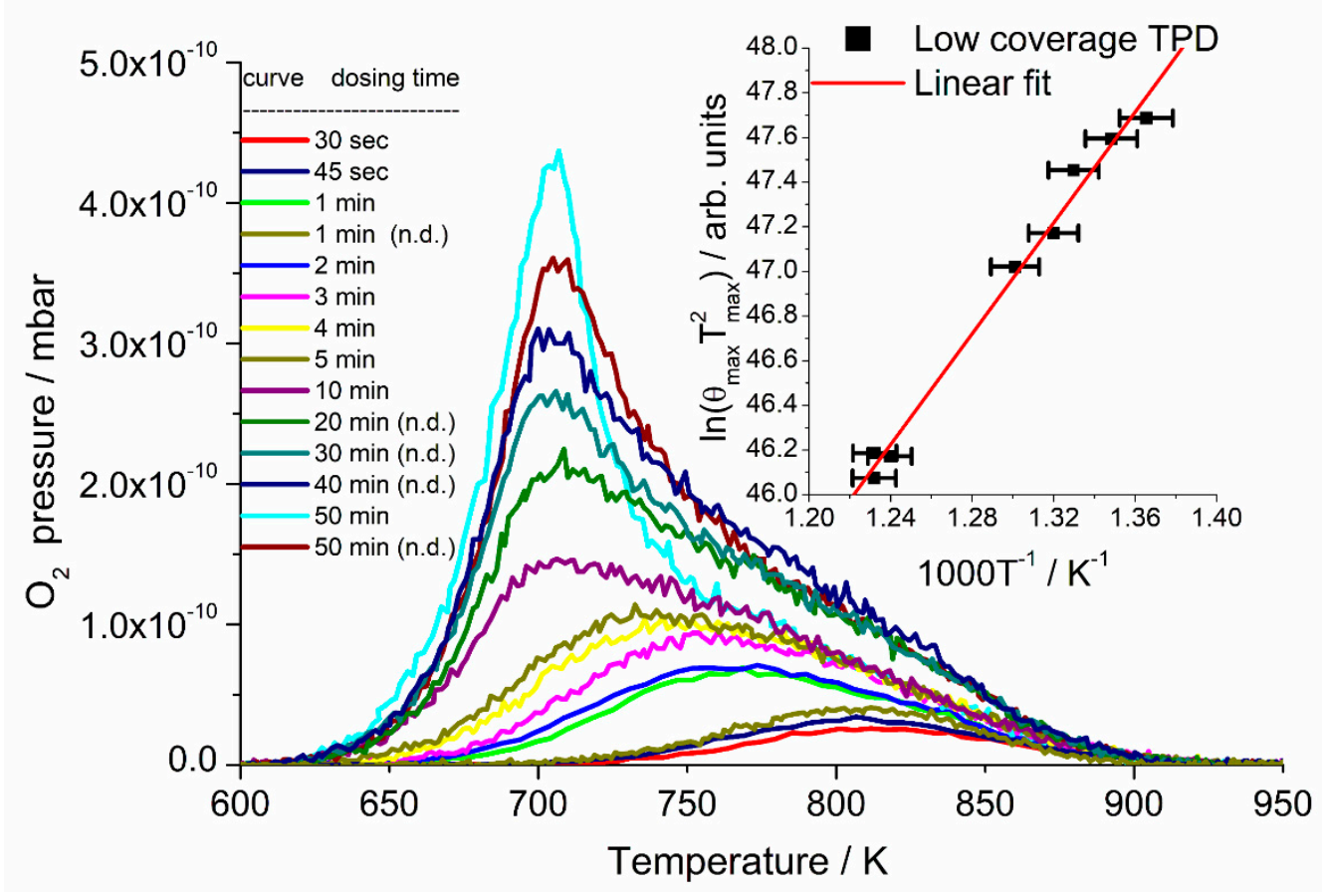

Figure 5. TPD-spectra of oxygen on $\mathrm{Pt}\{110\}$ for different exposures. The sample was dosed at $420 \mathrm{~K}$ with a pressure of $1 \times 10^{-8} \mathrm{mbar}_{2}$. The measurements were performed on two different days (indicated by n.d. for next day's results). Due to the extreme sensitivity of oxygen TPD to the surface structure, the TPD spectra of each day differ slightly from each other. The heating rate was $4 \mathrm{~K} / \mathrm{s}$. The insert shows a plot of the TPD peak maximum at low coverage according to equation (3) for exposures up to $5 \mathrm{~min}$.

From the coverage-dependent TPD spectra (Figure 5), we also calculated the desorption energy of the first-order peak using the Redhead equation. With the preexponential factor of $v_{1}=3.6 \times 10^{15 \pm 0.4} \mathrm{~s}^{-1}$ from the heating rate dependent measurements and the averaged value of the peak maximum temperature of $T_{\max }=706.4 \pm 0.6 \mathrm{~K}$, we found a desorption energy of $E_{d}=219.4 \pm 6.6 \mathrm{~kJ} / \mathrm{mol}$, in close agreement with the value obtained by our heating rate dependent measurement. Assuming a preexponential factor of $1 \times 10^{13} \mathrm{~s}^{-1}$, as used by Walker et al., gives a desorption energy of $184.8 \mathrm{~kJ} / \mathrm{mol}$, in good agreement with their value. Finally, assuming a preexponential factor of $1.7 \times 10^{9} \mathrm{~s}^{-1}$, as found by Wilf and Dawson, the desorption energy would be $133.8 \mathrm{~kJ} / \mathrm{mol}$, in agreement with their value.

For the second-order desorption peak, the data at lowest coverage were analyzed following Equation (3), where the subscript max indicates values recorded at the maximum in the second-order TPD peak.

$$
\ln \left[\frac{2 R T_{\max }^{2} \theta_{\max }}{\beta}\right]=\frac{E_{d}}{R T_{\max }}+\ln \left[\frac{E_{d}}{v_{2}}\right]
$$

We found from the gradient and intercept of the inset in Figure 5 that the activation energy for desorption is $E_{d}=103.2 \pm 4.4 \mathrm{~kJ} / \mathrm{mol}$ and the second-order prefactor $v_{2}$ is $4.2 \times 10^{-9 \pm 0.3} \mathrm{~cm}^{2}$ 
molecule ${ }^{-1} \mathrm{~s}^{-1}$. Wilf and Dawson found an average desorption energy of this $\beta_{2}$ state of $123 \mathrm{~kJ} / \mathrm{mol}$, with a preexponential factor of $6.5 \times 10^{-7} \mathrm{~cm}^{2}$ molecule $\mathrm{e}^{-1} \mathrm{~s}^{-1}$ [12].

Although the values for desorption energy and the preexponential factor differ significantly from author to author, the measurements are consistent with each other, as assuming a particular preexponential factor gives consistent values for the desorption energy for all measurements. The large scatter in the values for $v$ can be explained by the extreme sensitivity to slightly different peak maximum temperatures that result in a large uncertainty for this parameter. Simulations of the spectra are given in the Supplementary Materials, using a two-state model, and give reasonable fits to the experimental curves (Figure S4).

\subsection{CO Interaction with Pt $\{110\}$}

Figure 6 shows a high-temperature first-order desorption peak $\left(\beta_{1}\right)$ at $490 \mathrm{~K}$ for all coverages, with a second peak evolving at $398 \mathrm{~K}\left(\beta_{2}\right)$. This behavior is consistent with literature [37-39]. Using the Redhead equation assuming a frequency prefactor of $v=(4.5 \pm 1.5) \times 10^{14} \mathrm{~s}^{-1}$ (averaged from values of $v=6 \times 10^{14} \mathrm{~s}^{-1}$ found by Fair and Madix [39] and $v=3 \times 10^{14} \mathrm{~s}^{-1}$ found by Engstrom and Weinberg [16]), a value of $E_{d}=143( \pm 4) \mathrm{kJ} / \mathrm{mol}$ for the desorption activation energy for the $\beta_{1}$ desorption peak in the high-coverage region was obtained. This is in reasonable agreement with their values of $E_{d}=148 \mathrm{~kJ} / \mathrm{mol}[39]$ and $E_{d}=151( \pm 6) \mathrm{kJ} / \mathrm{mol}$ [16], but is rather different from the value of $E_{d}=129 \mathrm{~kJ} / \mathrm{mol}$ found by Comrie and Lambert [37] who assumed a frequency prefactor of $v=10^{13} \mathrm{~s}^{-1}$. Again, recalculating their experimental results with $v=4.5 \times 10^{14} \mathrm{~s}^{-1}$ gives a value of $E_{d}=144 \mathrm{~kJ} / \mathrm{mol}$, which is in perfect agreement with our result. For the low-temperature $\beta_{2}$ desorption peak, a desorption activation energy of $E_{d}=102( \pm 3) \mathrm{kJ} / \mathrm{mol}$ was calculated assuming a frequency prefactor of $v=10^{13} \mathrm{~s}^{-1}$. This value is in agreement with the values of $E_{d}=108 \mathrm{~kJ} / \mathrm{mol}$ found by Bonzel and $\mathrm{Ku}$ [38] and $E_{d}=$ $105 \mathrm{~kJ} / \mathrm{mol}$ found by Comrie and Lambert [37].

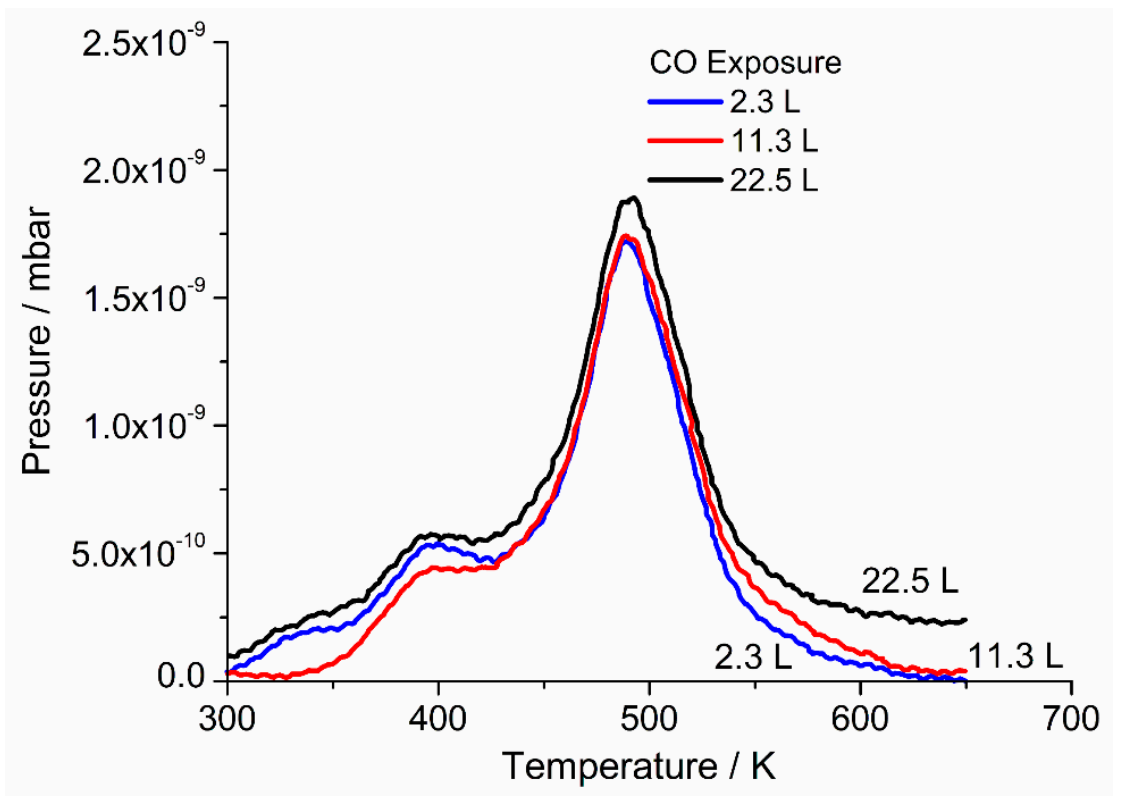

Figure 6. TPD-spectra of $\mathrm{CO}$ on $\mathrm{Pt}\{110\}$ for different exposures, as indicated in the figure. The sample was dosed at $200 \mathrm{~K}$ with a CO pressure of $5 \times 10^{-8}$ mbar. The heating rate was $3 \mathrm{~K} / \mathrm{s}$.

Our results for the initial sticking probability of $\mathrm{CO}$, and its saturation coverage, as a function of crystal temperature, on $\mathrm{Pt}\{110\}$ are shown in Figure 7. 


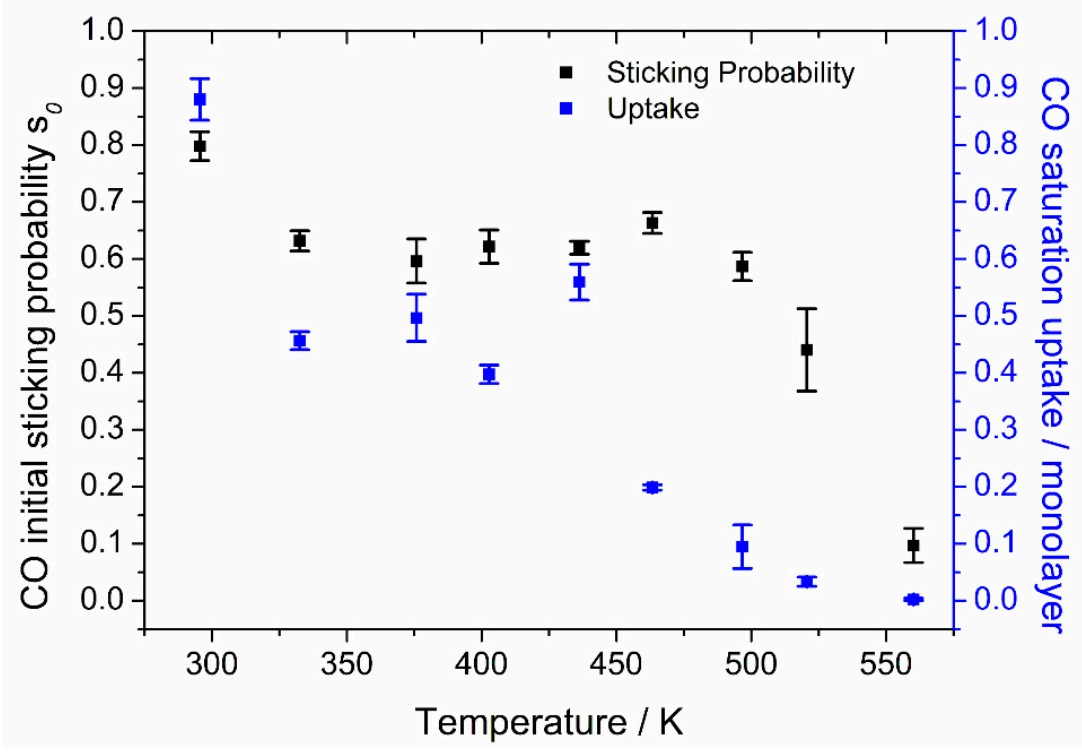

Figure 7. Initial sticking probability and saturation uptake of $\mathrm{CO}$ as a function of crystal temperature.

At $300 \mathrm{~K}$, we found a value of $0.80 \pm 0.04$, which is in good agreement with the values of 0.8 found by Fair and Madix [39] and 0.83 found by Wartnaby et al. [11]. Between 330 and $480 \mathrm{~K}$, the initial sticking probability $\left(s_{0}\right)$ stays almost constant at $0.62 \pm 0.04$. This is consistent with the conclusion of Fair and Madix [39] that the initial sticking probability is temperature independent over a wide region, although our values show an earlier decline in $s_{0}$ at temperatures above $480 \mathrm{~K}$ and the onset of a rise below $320 \mathrm{~K}$. Above $480 \mathrm{~K}$, the initial sticking probability falls steeply to 0 at $570 \mathrm{~K}$, due to entering the tail of the $\beta_{1}$ TPD desorption peak with a peak maximum temperature of $490 \mathrm{~K}$. The behavior of the initial sticking probability confirms the similarity in the $s_{0}$ values found for several different noble metal surfaces $(\operatorname{Rh}\{110\}, \operatorname{Pd}\{110\}, \operatorname{Rh}\{111\}$ and $\operatorname{Pd}\{111\}$ have values in the range $0.4-0.7$, as seen in [40] and references therein).

The saturation coverage values of the crystal for different temperatures were obtained from the total CO uptake by normalizing to a saturation coverage of $0.88 \mathrm{ML}$ at $300 \mathrm{~K}$. Saturation coverage declines with increasing temperature up to $490 \mathrm{~K}$, the CO TPD peak maximum temperature. For higher temperatures, it shows a slight drop to very low values, finally reaching zero coverage at $570 \mathrm{~K}$.

The sticking probability curves of CO (an example is shown in Figure 8) show precursor-mediated adsorption behavior [11]. CO is trapped into a weakly held mobile precursor state, which can be described as a two-dimensional gas [39]. This mobility gives the possibility of finding sites for adsorption on the surface even if the arrival site is blocked. Some of our sticking curves have been fitted by the Kisliuk expression [41], Equation (4).

$$
\frac{s}{s_{0}}=\frac{1-\theta}{1+(\mathrm{K}-1) \theta}
$$

where $s$ is the instantaneous sticking probability, $s_{0}$ is the initial (zero coverage) sticking probability and $\theta$ is the relative coverage of the crystal surface for a particular temperature, normalized to saturation coverage. The parameter $\mathrm{K}$ describes the mobility of the precursor state with small values for a highly mobile precursor and a value of $K=1$ for an immobile precursor, which gives rise to the Langmuir adsorption isotherm. 


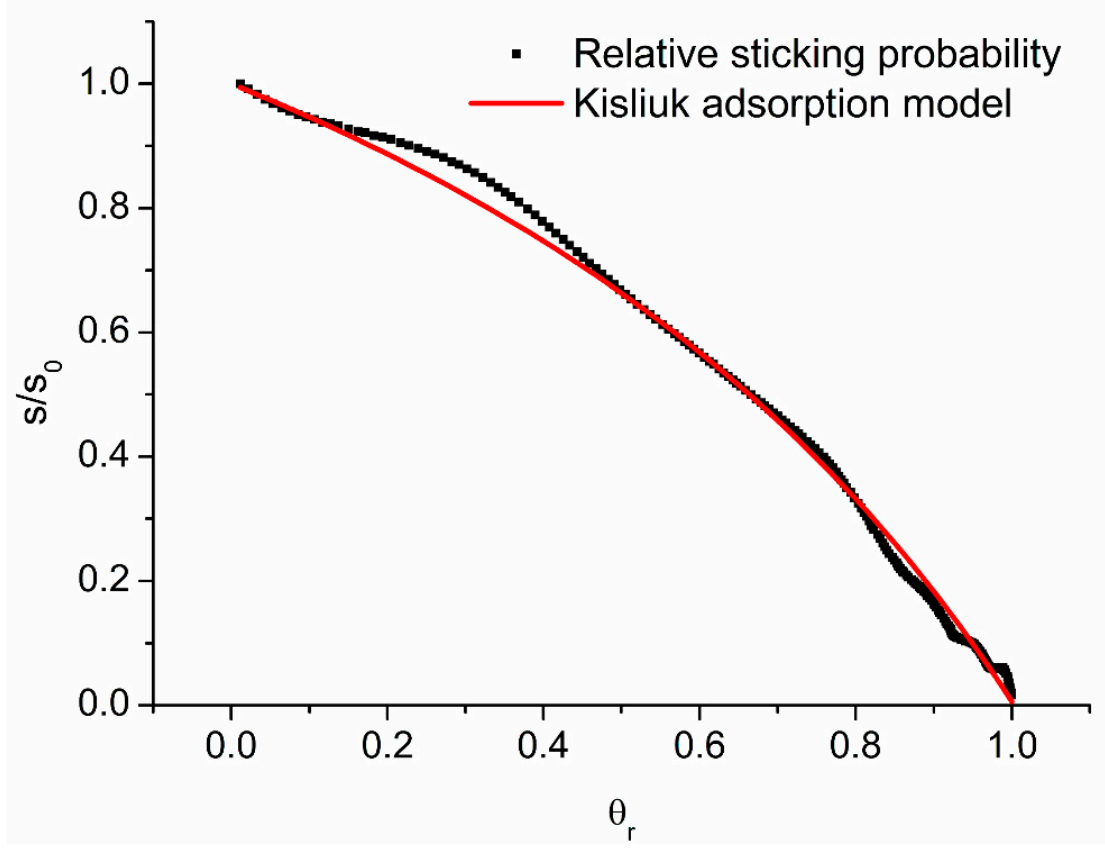

Figure 8. Plot of relative sticking probability $s / s_{0}$ versus relative coverage $\theta$ for CO sticking at $450 \mathrm{~K}$ (solid line). The corresponding Kisliuk fit is shown as a red line.

The results for the temperature dependence of $\mathrm{K}$ are shown in Figure 9:

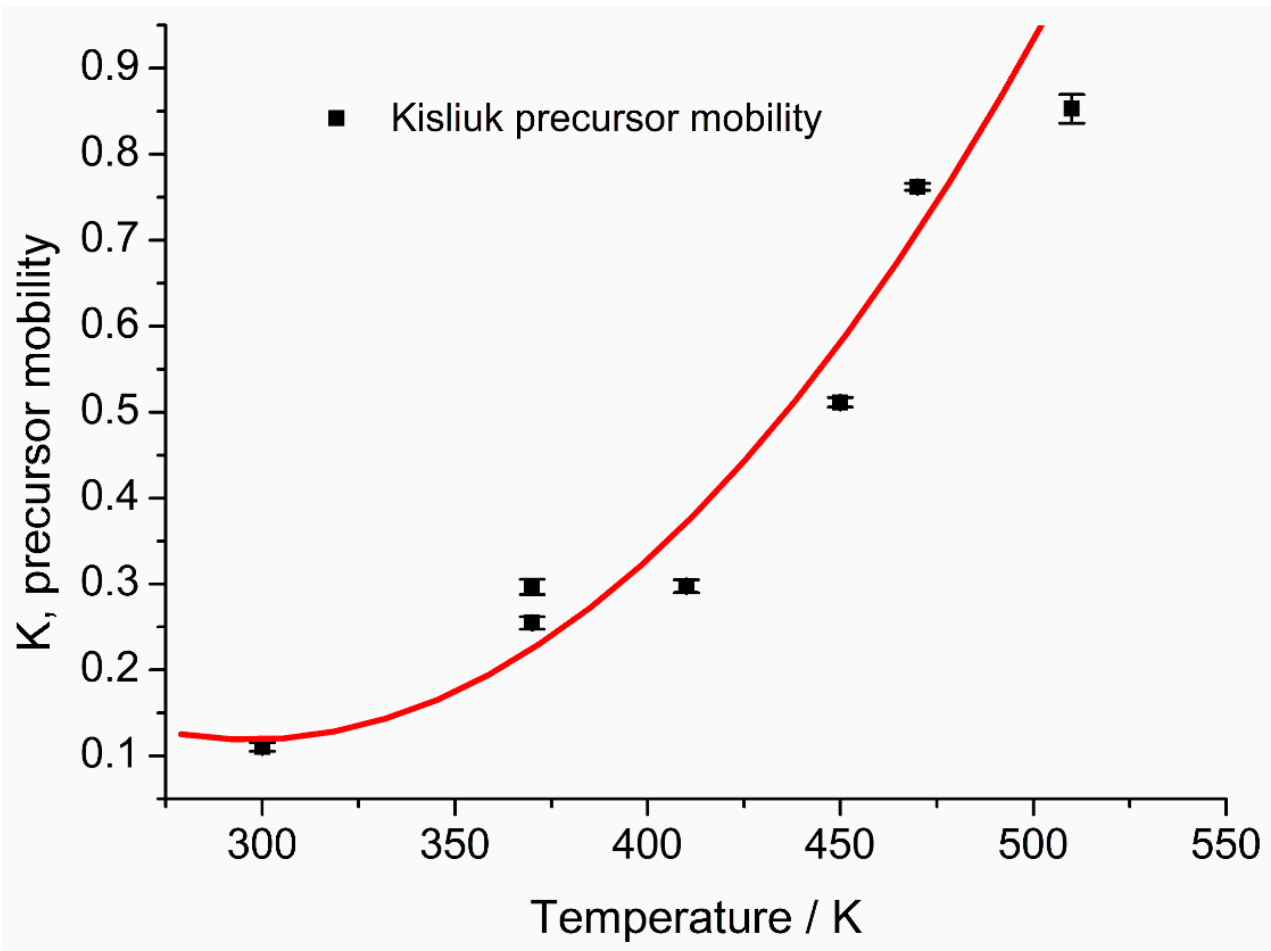

Figure 9. The dependence of the Kisliuk precursor mobility parameters for $\mathrm{CO}$ adsorption on $\mathrm{Pt}\{110\}$ with temperature.

It shows a strong tendency towards higher values and thus less mobile precursors with increasing temperature, due to a shorter lifetime of the precursor state and a reduced number of site visits. Th value of $\mathrm{K}=0.11( \pm 0.01)$ found for $300 \mathrm{~K}$ is low compared to the value of 0.25 found by Wartnaby et al. [11]. 
In contrast, a value of 0.13 at $327 \mathrm{~K}$ for $\mathrm{CO}$ adsorption on $\mathrm{Pd}\{110\}$ found by Jones et al. [38] fits well to our values, again indicating similarity of these surfaces regarding $\mathrm{CO}$ adsorption.

\subsection{CO Oxidation}

Steady-state Temperature Programmed Reaction (TPR) experiments were carried out with different $\mathrm{CO} / \mathrm{O}_{2}$ ratios in the beam. Initially, when introduced to the clean surface at $373 \mathrm{~K}$, the mixed beam produces $\mathrm{CO}_{2}$ until the surface is covered with $\mathrm{CO}$ (Figure 10). With a high $\mathrm{CO} / \mathrm{O}_{2}$ ratio, the $\mathrm{CO}_{2}$ evolution stops quickly (after $\sim 25 \mathrm{~s}$ of reaction) due to surface poisoning with $\mathrm{CO}$, whereas at a low ratio it seems to reach near steady-state $\mathrm{CO}_{2}$ evolution.

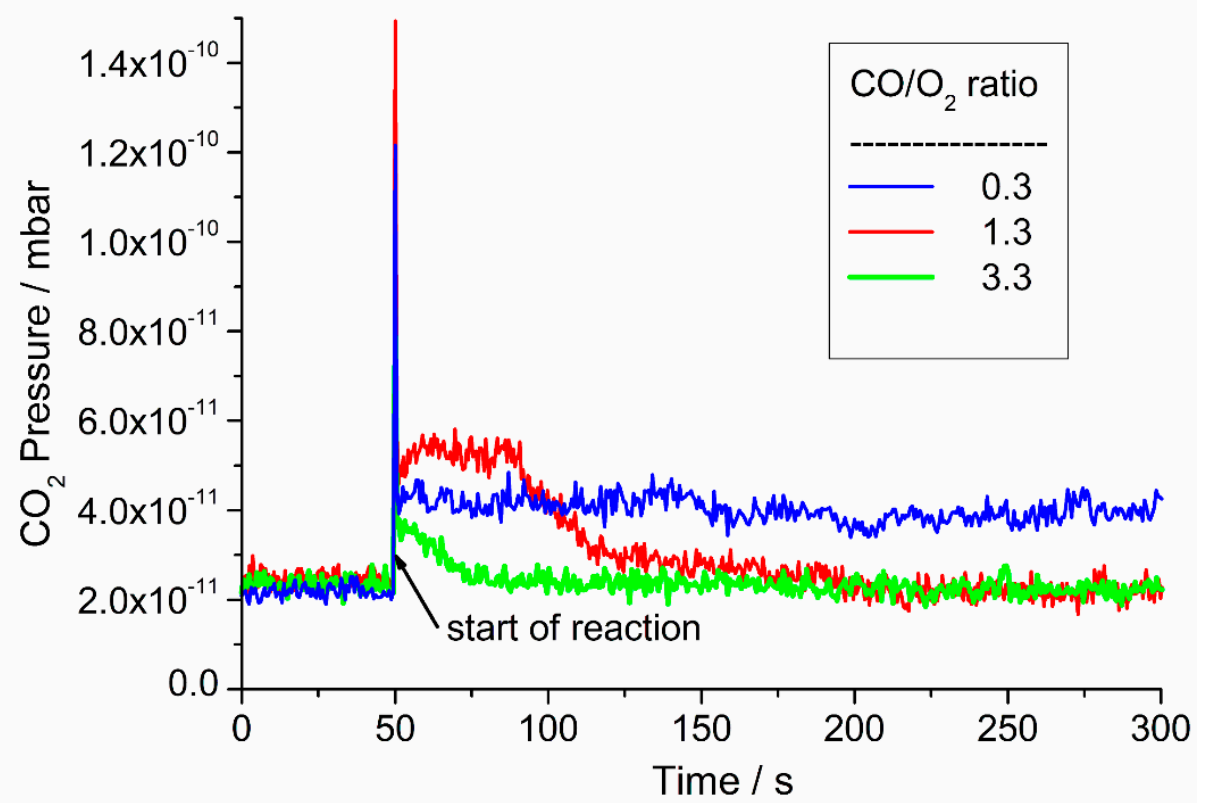

Figure 10. $\mathrm{CO}_{2}$ evolution during the introduction of a mixture of $\mathrm{CO}$ and oxygen on a clean $\mathrm{Pt}\{110\}$ surface with a molecular beam at a constant temperature of $370 \mathrm{~K} . \mathrm{CO} / \mathrm{O}_{2}$ ratios are 0.3 (blue curve), 1.3 (red curve) and 3.3 (green curve).

If the $\mathrm{CO}$ poisoned surface is taken to higher temperatures when the $\mathrm{CO}$ desorption becomes appreciable, oxygen can adsorb and thus CO oxidation is made possible (Figure 11). This "light-off" of the steady-state reaction takes place in the temperature region between 460 and $510 \mathrm{~K}$ (which is also the $\beta_{1} \mathrm{CO}$ desorption temperature range). At low $\mathrm{CO} / \mathrm{O}_{2}$ ratios, the surface is not initially poisoned with $\mathrm{CO}$. The $\mathrm{CO}_{2}$ production shows therefore a steady decrease with temperature as the coverage of $\mathrm{CO}$ decreases with increasing temperature. The highest rate is achieved with the ratio nearest to 1 .

Angle-resolved CO oxidation measurements were performed at temperatures of 470-620 K, slightly above the $\mathrm{CO}$ desorption temperature to avoid surface poisoning and to keep a steady state of reaction. A high temperature was also necessary to keep the $\mathrm{CO}$ equilibrium coverage low, as at temperatures above $250 \mathrm{~K}$ and CO coverages of more than $0.2 \mathrm{ML}$, the phase transition $(1 \times 2) \rightarrow(1 \times 1)$ takes place $[9,42]$. Steady-state experiments that were performed at room temperature or below, even at $\mathrm{CO} / \mathrm{O}_{2}$ ratios that should ensure that no surface poisoning occurred, showed too low a signal to noise ratio and therefore could not be evaluated. For the angle-resolved measurements, the $\mathrm{CO}_{2}$ flux was measured in the $[1 \overline{1} 0]$ plane. To achieve a high $\mathrm{CO}_{2}$ signal, a pressure ratio $1: 1$ of $\mathrm{CO} / \mathrm{O}_{2}$ was used in the beam. 


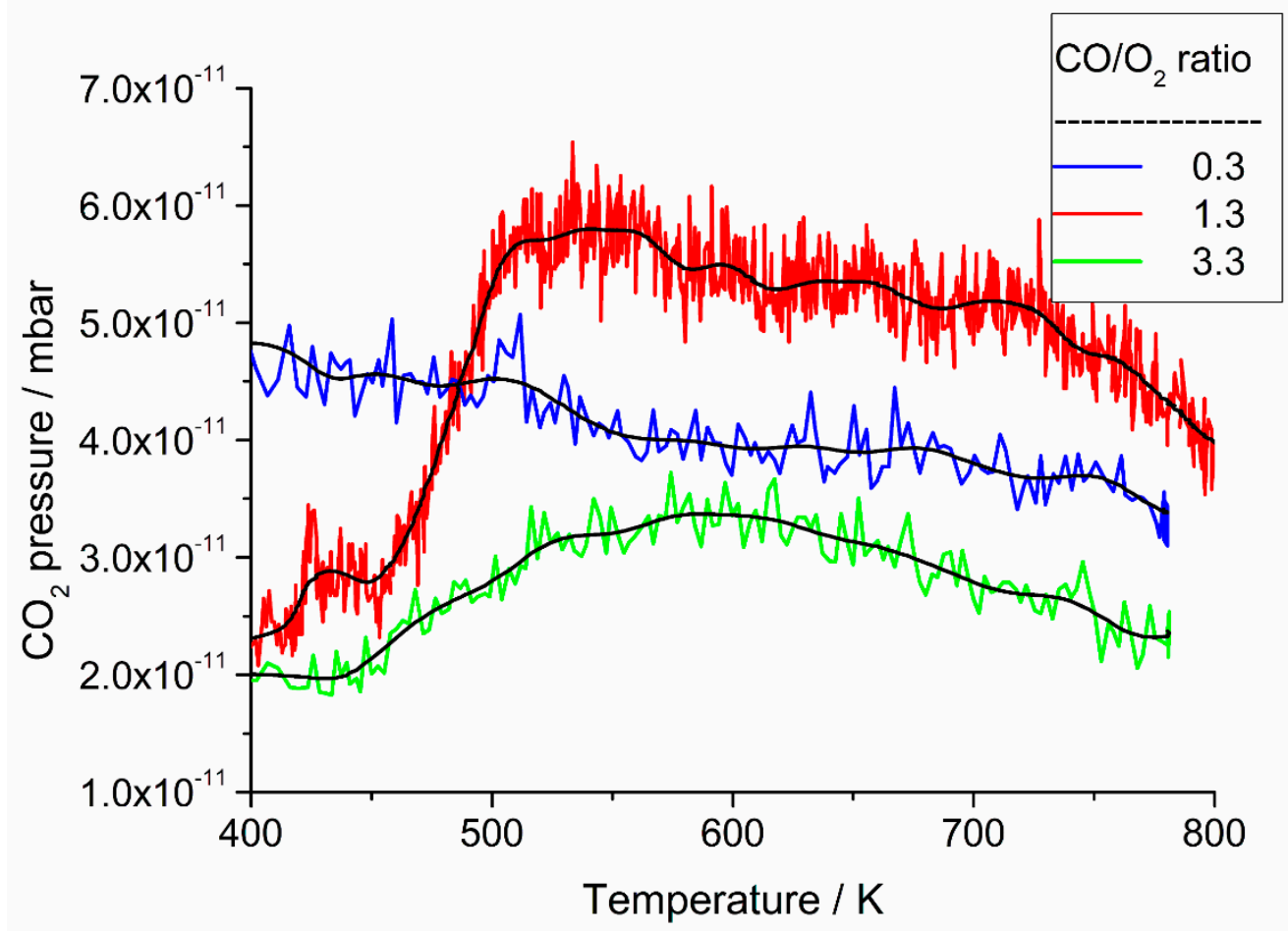

Figure 11. Pseudo-steady-state $\mathrm{CO}_{2}$ evolution while ramping the surface temperature at $4 \mathrm{~K} / \mathrm{s}$. The crystal was supplied with a constant flux of $\mathrm{CO}$ and oxygen from the molecular beam. $\mathrm{CO} / \mathrm{O}_{2}$ ratios as in Figure 10.

The resulting curves showed a broad distribution over the measured angular range, but, for temperatures above $470 \mathrm{~K}$, three components are clearly visible. The curves were deconvoluted into cosine power functions using a numerical least-square fit (Simplex and Levenberg-Marquardt algorithms) to the function given in Equation (5).

$$
I(\theta)=I_{0}+I_{1} \cos ^{\alpha_{1}}\left(\theta-x_{1}\right)+I_{2} \cos ^{\alpha_{2}}\left(\theta-x_{2}\right)+I_{3} \cos ^{\alpha_{3}}\left(\theta-x_{3}\right)
$$

with $I(\theta)$ the signal intensity for the crystal polar angle $\theta, I_{0}$ the baseline height, $I_{1}-I_{3}$ the peak heights, $\alpha_{1}-\alpha_{3}$ their exponents and $x_{1}-x_{3}$ their angular positions. The two extreme temperatures are shown in Figures 12 and 13, while the other scattering distributions at 523 and $573 \mathrm{~K}$ are given in the Supplementary Materials (Figure S5a,b). The low temperature distribution is quite different from the other three, which are all fairly similar in shape. The computed best fit parameters for the different temperatures are listed in Table 1.

In all four cases two lobes were evident at angles of about $\pm 16^{\circ}$ from the $\mathrm{Pt}\{110\}$ surface normal, appearing at approximately $74^{\circ}$ and $106^{\circ}$. We could not discriminate a crystal surface normal peak in our data. The inclined angles for product evolution may be attributed to $\mathrm{CO}_{2}$ desorption normal to the reaction sites on the $\{111\}$ microfacets, and therefore shows sensitivity to the local structure in the reaction, rather than average surface plane dependence. That is, the $\mathrm{CO}_{2}$ is generated at such sites and desorbs directly over the lowest barrier directly into the gas phase in a direction perpendicular to the local potential energy surface.

At the transition state of the reaction, the O-CO complex forms on a highly repulsive potential energy surface with respect to the local facet and the formation of $\mathrm{CO}_{2}$ leads to ejection of the molecule with excess kinetic energy (in comparison to thermal). This kinetic energy leads to a high velocity perpendicular to the reaction site in comparison to lateral thermal motion and hence is characterized by a high exponent in the cosine fits (typically $\alpha$ is 10-20). 


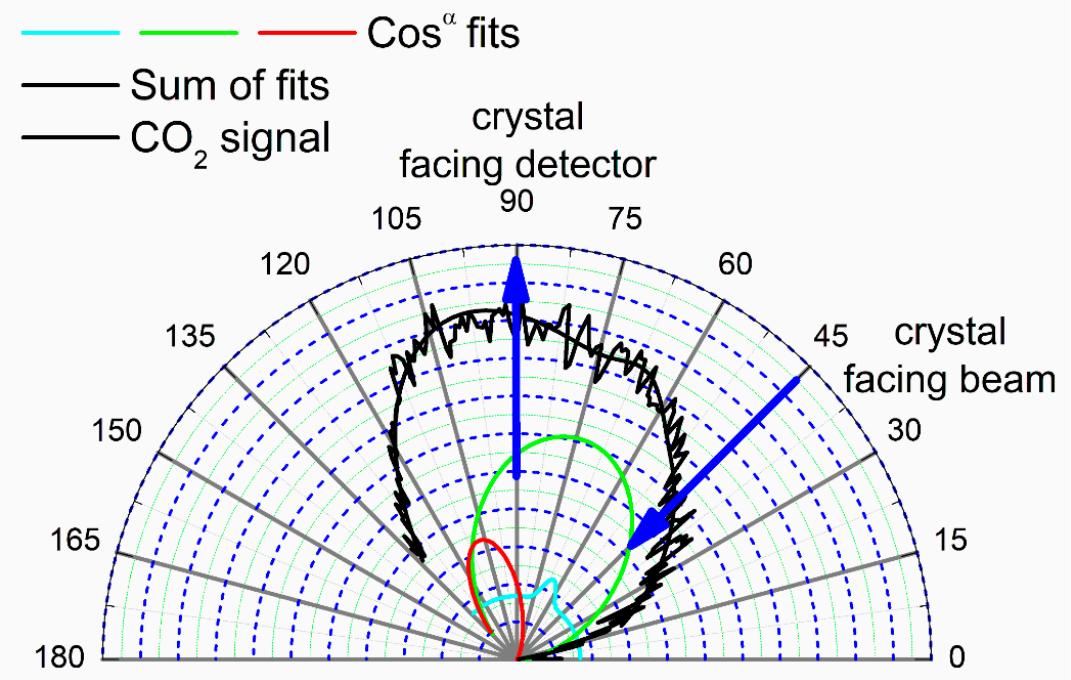

Figure 12. Angle-resolved $\mathrm{CO}$ oxidation experiment at $T=473 \mathrm{~K}$. The $\mathrm{CO}_{2}$ signal intensity is plotted as a function of the crystal polar angle. Three $\operatorname{cosine}^{\alpha}$-shaped peaks are fitted simultaneously, and their sum are shown as solid lines.

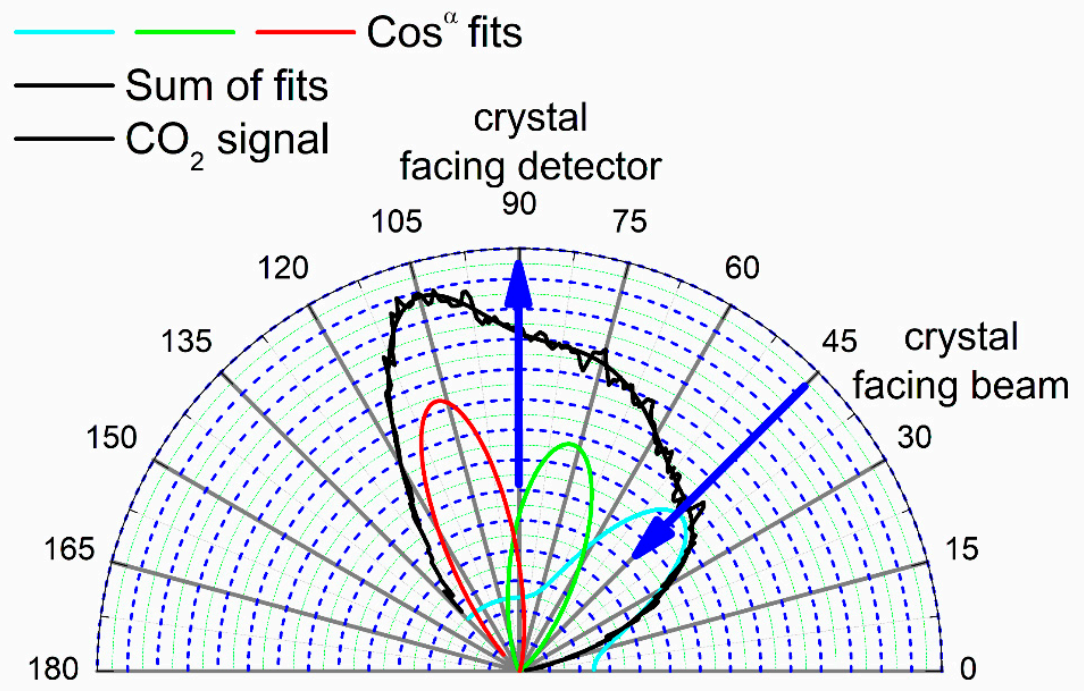

Figure 13. As in Figure 12, but at $623 \mathrm{~K}$ surface temperature.

Table 1. $\mathrm{CO}_{2}$ angular desorption parameters from fitting of profiles in steady-state $\mathrm{CO}$ oxidation from $\operatorname{Pt}\{110\}-(1 \times 2)$ at four surface temperatures. Angles $x_{1}-x_{3}$ are highlighted and $\mathrm{R}^{2}$, the coefficient of determination, for each fit is given. Data at 523 and $573 \mathrm{~K}$ are shown in Figure S5a,b.

\begin{tabular}{ccccc}
\hline Temperature/K & $\mathbf{4 7 3}$ & $\mathbf{5 2 3}$ & $\mathbf{5 7 3}$ & $\mathbf{6 2 3}$ \\
\hline$I_{0}$ & $1.68 \pm 0.86$ & $1.14 \pm 0.46$ & $0.99 \pm 0.51$ & $2.44 \pm 0.24$ \\
$I_{1}$ & $0.64 \pm 0.30$ & $5.77 \pm 0.60$ & $6.78 \pm 0.66$ & $4.97 \pm 0.42$ \\
$x_{1}$ & $65.4 \pm 1.6$ & $43.2 \pm 2.0$ & $43.6 \pm 2.1$ & $44.0 \pm 1.7$ \\
$\alpha_{1}$ & $130.6 \pm 129.2$ & $14.6 \pm 3.7$ & $12.2 \pm 2.9$ & $17.0 \pm 3.0$ \\
$I_{2}$ & $6.09 \pm 0.98$ & $7.06 \pm 0.42$ & $7.70 \pm 0.66$ & $7.70 \pm 0.20$ \\
$x_{2}$ & $73.9 \pm 7.3$ & $74.3 \pm 1.4$ & $74.2 \pm 1.3$ & $77.0 \pm 1.1$ \\
$\alpha_{2}$ & $2.74 \pm 0.94$ & $19.1 \pm 2.7$ & $19.2 \pm 2.2$ & $15.0 \pm 2.1$ \\
$I_{3}$ & $3.32 \pm 1.69$ & $10.6 \pm 0.5$ & $11.9 \pm 0.5$ & $9.35 \pm 0.33$ \\
$x_{3}$ & $107.3 \pm 0.1$ & $105.8 \pm 0.1$ & $105.6 \pm 0.1$ & $107.2 \pm 0.1$ \\
$\alpha_{3}$ & $10.9 \pm 4.9$ & $15.8 \pm 1.6$ & $14.5 \pm 1.2$ & $21.9 \pm 1.3$ \\
$\mathrm{R}^{2}$ & 0.968 & 0.993 & 0.986 & 0.988 \\
\hline
\end{tabular}


The third peak in $\mathrm{CO}_{2}$ evolution that appears with the crystal oriented at $\sim 44^{\circ}$ does not correspond to a facet or a surface normal. We believe that this peak is likely to be due to the angle dependence of the absolute amount of produced $\mathrm{CO}_{2}$. The angle integrated mass spectrometer showed a maximum in the $\mathrm{CO}_{2}$ production at the facing beam position, so the third peak can be attributed to this maximum.

In an angle-resolved TPD study, Matsushima et al. found desorption angles of $\pm 25^{\circ}$ for a $\mathrm{CO}_{2}$ formation peak at $310 \mathrm{~K}$ and $\pm 23^{\circ}$ for a $\mathrm{CO}_{2}$ formation peak at $410 \mathrm{~K}$ [20]. They explained the difference between facet angles and desorption angles with effects of conducting electrons and surface distortions (see Introduction). Their method to deconvolute the measured curves in single peaks was to fit two peaks to the outer parts of the curves assuming symmetrical behavior and to subtract these two peaks from the measured curve to get a third peak centered at the surface normal. For several reasons, this approach is inappropriate for our data: at very grazing angles between surface and beam, the beam is spread across the face of the crystal and will overspill the edges leading to a dramatic drop in apparent reaction products until at an angle of $135^{\circ}$ the beam will only hit the side of the crystal. The steep decrease at high angles is therefore an artificial effect, as described in Figure S1. This inherent asymmetry in our experimental geometry therefore dictates our analysis approach.

Despite these difficulties, the achieved angles for the lobes are only slightly below the values obtained by Matsushima et al. [20,24], but, importantly, we ran a continuous angle-resolved experiment under low coverage steady-state reaction conditions. At $470 \mathrm{~K}$, there are no obvious peaks in the curve, although the computed best fit also showed two peaks at $\sim \pm 17^{\circ}$ from the surface normal. It may well be that at $470 \mathrm{~K}$ the surface coverage of $\mathrm{CO}$ is sufficient to initiate a partial $(1 \times 2) \rightarrow(1 \times 1)$ phase transition. This would be expected to decrease the amount of $\mathrm{CO}_{2}$ that desorbs from the $\{111\}$ microfacets of the $\mathrm{Pt}\{110\}-(1 \times 2)$ surface. The newly formed $(1 \times 1)$ surface has lower corrugation and so will not show such distinct facet desorption.

Note that Neugebohren et al. [1] mapped velocity-resolved rates of carbon monoxide at stepped platinum surfaces and found two distinct channels for reaction, being dominated at low temperatures by the more active step sites and at high temperatures by the more abundant terrace sites. The temperature switch between channels is at $\sim 700 \mathrm{~K}$ under their supersonic conditions. Our work is in the temperature regime below this, where step sites on an otherwise flat surface might be most active. Of course, in the work here, effectively all sites are step sites on $\mathrm{Pt}\{110\}$, but the $\{111\}$-facetted $(1 \times 2)$ surface dominates the distribution of evolving, activated $\mathrm{CO}_{2}$ molecules.

\section{Experimental}

The experiments were carried out in an ultra-high vacuum chamber (VG Scientific, East Grinstead, UK) (Figure 14) pumped by a diffusion pump (Edwards Ltd, Burgess Hill, UK) and an additional titanium sublimation pump (VG) to give a base pressure below $10^{-10}$ mbar.

The $P \mathrm{t}\{110\}$ crystal was mounted centrally in the chamber on a manipulator capable of moving in the $\mathrm{X}, \mathrm{Y}$ and $\mathrm{Z}$ directions as well as rotating the crystal around its polar and azimuthal axes (Figure 14). Both axes were equipped with stepper motors (VG) to allow automated angle-resolved experiments by preprograming sequences of temperature ramps and angular movements. The crystal was held by two tungsten wires spot-welded to its side, which were also used for conductive heating. For low-temperature experiments, the crystal could be cooled down to $120 \mathrm{~K}$ by liquid nitrogen cooling. The temperature of the crystal was measured by a K-type thermocouple (Goodfellow, Cambridge, UK) spot-welded to the rear face. 


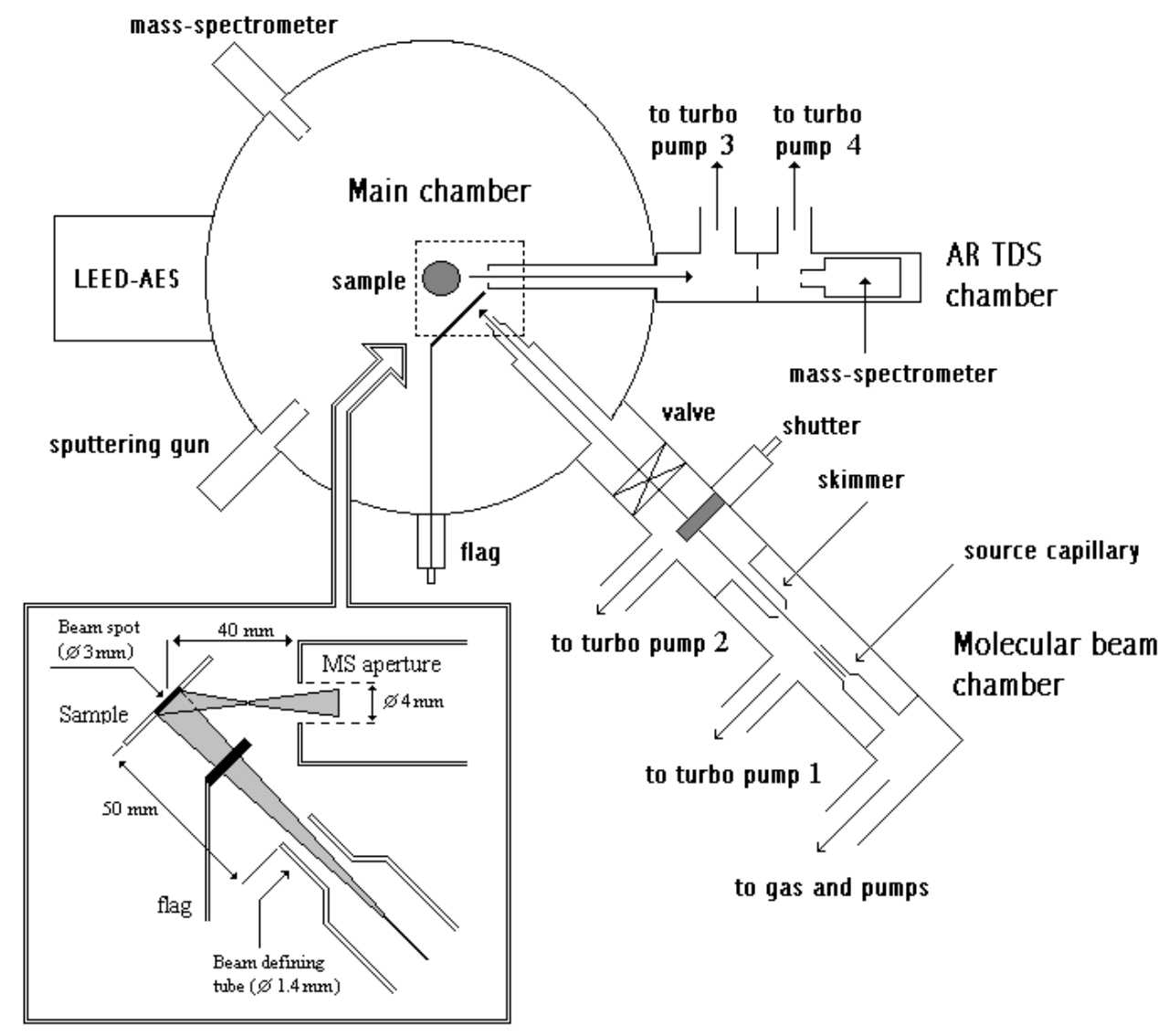

Figure 14. Schematic diagram of the molecular beam apparatus. The small insert illustrates the angle-resolved experimental facility.

Gases could be dosed onto the crystal surface either via leak valves (VG) (background dosing) or using a thermal molecular beam attached to the chamber, normally operated at $\sim 40$ mbar source pressure. The beam could be shut off using a computer-controllable shutter inside the beam system and a gold flag in the chamber right between beam nozzle and crystal. The beam was sharply collimated to give a spot of 3-mm diameter. The resulting beam flux was calculated from the sticking measurements with $\mathrm{O}_{2}$ to be $\mathrm{F}=1.2( \pm 0.4) \times 10^{18}$ molecules $\mathrm{m}^{-2} \mathrm{~s}^{-1}$ for a source pressure of $40 \mathrm{mbar}$. For this calculation, an $\mathrm{O}_{2}$ "saturation" coverage of 0.6 was assumed in the temperature range of 300-400 K.

Angle-integrated experiments could be performed using a quadrupole mass spectrometer (MS, Hiden Analytical, Warrington, UK) built into the main chamber without line of sight of the sample to analyze the background gas. A second quadrupole mass analyzer was situated in a differentially pumped side chamber at an angle of $45^{\circ}$ to the molecular beam behind two collimator apertures to allow angle-resolved observations. Both spectrometers ran concurrently and analog inputs on both instruments were used to record sample temperature, orientation and molecular beam pressure synchronized with the MS data.

The chamber was further equipped with an argon ion sputter gun and a LEED/AES unit for crystal cleaning and confirming surface order and cleanliness, respectively. The crystal was cleaned by sputtering with argon ions, followed by heating in oxygen at $700 \mathrm{~K}$ and $5 \times 10^{-8}$ mbar for $30 \mathrm{~min}$. Finally, the crystal was annealed at $970 \mathrm{~K}$ for $10 \mathrm{~min}$. Cleanliness of the surface was checked by LEED (VG) and oxygen TPD measurements. The sample was aligned by hand while viewing the LEED to give datums for azimuth and polar angle motors.

Temperature programmed desorption, and sticking experiments using the King and Wells technique [25] could be performed in the machine. Temperature programmed reaction (TPR) 
experiments could also be made on a pseudo-steady-state basis by beaming gases at the crystal surface while ramping surface temperature [26]. Angle-resolved experiments could be performed under steady-state conditions by beaming gas at the crystal surface while automatically turning the crystal around the polar axis and recording the angle-dependent flux of molecules with the mass spectrometer in the side chamber. Typically, this could be achieve in $200 \mathrm{~s}$. The yield curves were normalized by baseline subtraction and division by the beam source pressure (there is a linear dependency of the beam flux on the source pressure for $\mathrm{P}<70 \mathrm{mbar}$ ) to obtain comparable values. They were averaged over several experiments for noise reduction. Calibration of the sticking measurements is described in the Supplementary Materials.

\section{Conclusions}

We constructed a simple thermal molecular beam reactor which can determine the angular distribution of products from surface reactions under in-situ steady-state reaction conditions in a fast, efficient manner. It can also be done in a pseudo-steady state, temperature-programmed manner. Product scattering during CO oxidation could be achieved in about $200 \mathrm{~s}$. The products are resolved into two components at high temperature which desorb at $\sim \pm 16^{\circ}$, close to the normal to the $\{111\}$ microfacets of the $\mathrm{Pt}\{110\}-(1 \times 2)$ surface. We determined the sticking probabilities and desorption energies of oxygen and $\mathrm{CO}$ and show that reaction between them only occurs at steady state at low $\mathrm{CO}: \mathrm{O}_{2}$ ratios at low temperature, but can occur at high $\mathrm{CO}: \mathrm{O}_{2}$ ratios at elevated temperature.

Supplementary Materials: The following are available online at http://www.mdpi.com/2073-4344/10/11/1229/s1, Figure S1: Apparent initial sticking probability $s_{0, \text { app }}$ of oxygen at $420 \mathrm{~K}$, Figure S2: He, Ar and O2 scattering from $\mathrm{Pd}(111)$ at 373, 573 and $873 \mathrm{~K}$, respectively, Figure S3: Sticking probability of oxygen as a function of uptake for different sample temperatures, Figure S4: Simulated oxygen TPD spectra, Figure S5: Angle-resolved CO oxidation at 523 and $573 \mathrm{~K}$ surface temperature.

Author Contributions: Conceptualization, M.B. and R.A.B.; methodology, B.U.K. and K.L.; software, R.A.B., B.U.K. and K.L.; formal analysis, M.B., B.U.K., K.L. and R.A.B.; investigation, B.U.K., K.L. and R.A.B.; resources, M.B.; writing-original draft preparation, B.U.K. and K.L.; writing—review and editing, R.A.B. and M.B.; visualization, R.A.B.; supervision, M.B. and R.A.B.; project administration, M.B.; and funding acquisition, M.B. All authors have read and agreed to the published version of the manuscript.

Funding: This research was funded by EPSRC, grant numbers EP/R026939/1 and EP/R026815/1.

Acknowledgments: K.L. and B.U.K are grateful for student mobility grants within the ERASMUS program of the EU.

Conflicts of Interest: The authors declare no conflict of interest. The funders had no role in the design of the study; in the collection, analyses, or interpretation of data; in the writing of the manuscript, or in the decision to publish the results.

\section{References}

1. Neugebohren, J.; Borodin, D.; Hahn, H.W.; Altschäffel, J.; Kandratsenka, A.; Auerbach, D.J.; Campbell, C.T.; Schwarzer, D.; Harding, D.J.; Wodtke, A.M.; et al. Velocity-resolved kinetics of site-specific carbon monoxide oxidation on platinum surfaces. Nature 2018, 558, 280-283. [CrossRef]

2. Lahee, A.M.; Allison, W.; Willis, R.F.; Rieder, K.H. He diffraction studies of Pt(110) $(1 \times 2)$. Surf. Sci. 1983, 126, 654-660. [CrossRef]

3. Kellogg, G.L. Direct Observations of the $(1 \times 2)$ Surface Reconstruction on the Pt(110) Plane. Phys. Rev. Lett. 1985, 55, 2168-2171. [CrossRef]

4. Daw, M.S. Calculations of the energetics and structure of $\mathrm{Pt}(110)$ reconstruction using the embedded atom method. Surf. Sci. Lett. 1986, 166, L161-L168.

5. Gritsch, T.; Coulman, D.; Behm, R.J.; Ertl, G. Mechanism of the CO-induced $1 \times 2 \rightarrow 1 \times 1$ structural transformation of Pt(110). Phys. Rev. Lett. 1989, 63, 1086-1089. [CrossRef] [PubMed]

6. Jackman, T.E.; Davies, J.A.; Jackson, D.P.; Norton, P.R.; Unertl, W.N. A new surface phase for CO-covered Pt(110). J. Phys. C Solid State Phys. 1982, 15, L99-L104. [CrossRef]

7. Freyer, N.; Kiskinova, M.; Pirug, G.; Bonzel, H.P. Oxygen adsorption on Pt(110)- $(1 \times 2)$ and Pt $(110)-(1 \times 1)$. Surf. Sci. 1986, 166, 206-220. [CrossRef] 
8. Schwegmann, S.; Tappe, W.; Korte, U. Quantitative structure analysis of a disordered system: RHEED study of the CO induced $(1 \times 2) \rightarrow(1 \times 1)$ structure transition of $\operatorname{Pt}(110)$. Surf. Sci. 1995, 334, 55-76. [CrossRef]

9. Von Oertzen, A.; Rotermund, H.H.; Nettesheim, S. Diffusion of carbon monoxide and oxygen on Pt(110): Experiments performed with the PEEM. Surf. Sci. 1994, 311, 322-330. [CrossRef]

10. Hofmann, P.; Bare, S.R.; King, D.A. Surface phase transitions in co chemisorption on Pt\{110\}. Surf. Sci. 1982, 117, 245-256. [CrossRef]

11. Wartnaby, C.E.; Stuck, A.; Yeo, Y.Y.; King, D.A. Microcalorimetric Heats of Adsorption for CO, NO, and Oxygen on Pt\{110\}. J. Phys. Chem. 1996, 100, 12483-12488. [CrossRef]

12. Wilf, M.; Dawson, P.T. The adsorption and desorption of oxygen on the $\mathrm{Pt}(110)$ surface; A thermal desorption and LEED/AES study. Surf. Sci. 1977, 65, 399-418. [CrossRef]

13. Walker, A.V.; Klötzer, B.; King, D.A. Dynamics and kinetics of oxygen dissociative adsorption on $\mathrm{Pt}\{110\}(1 \times 2)$. J. Chem. Phys. 1998, 109, 6879-6888. [CrossRef]

14. Wartnaby, C.E.; Stuck, A.; Yeo, Y.Y.; King, D.A. Calorimetric measurement of catalytic surface reaction heat: CO oxidation on Pt $\{110\}$. J. Chem. Phys. 1995, 102, 1855-1858. [CrossRef]

15. Campbell, C.T.; Ertl, G.; Kuipers, H.; Segner, J. A molecular beam study of the catalytic oxidation of CO on a Pt(111) surface. J. Chem. Phys. 1980, 73, 5862-5873. [CrossRef]

16. Engstrom, J.R.; Weinberg, W.H. Analysis of gas-surface reactions by surface temperature modulation: Experimental applications to the adsorption and oxidation of carbon monoxide on the $\mathrm{Pt}(110)-(1 \times 2)$ surface. Surf. Sci. 1988, 201, 145-170. [CrossRef]

17. Bonzel, H.P.; Ku, R. Mechanisms of the catalytic carbon monoxide oxidation on Pt (110). Surf. Sci. 1972, 33, 91-106. [CrossRef]

18. Ohno, Y.; Matsushima, T.; Uetsuka, H. Angular and velocity distributions of desorbing product carbon dioxide from two reaction sites on platinum(110) $(1 \times 2)$. J. Chem. Phys. 1994, 101, 5319-5328. [CrossRef]

19. Matsushima, T.; Ohno, Y.; Murakami, J.-I. Spatial and velocity distributions of desorbing product carbon dioxide over a reconstructed platinum $(110)(1 \times 2)$ surface. Surf. Sci. 1993, 287, 192-195. [CrossRef]

20. Matsushima, T.; Shobatake, K.; Ohno, Y. Spatial and velocity distributions of product desorption in carbon monoxide oxidation over palladium $(110)$ and reconstructed platinum $(110)(1 \times 2)$ surfaces. Surf. Sci. 1993, 283, 101-108. [CrossRef]

21. Sowa, E.C.; Vanhove, M.A.; Adams, D.L. The Missing-Row Model For The Reconstructed Pt(110)-(1x2) Surface-A Leed Intensity Analysis Showing Multilayer Distortions. Surf. Sci. 1988, 199, 174-182. [CrossRef]

22. Masson, F.; Rabalais, J.W. Time-of-flight scattering and recoiling spectrometry (TOF-SARS) analysis of Pt $\{110\}$ : I. Quantitative structural study of the clean $(1 \times 2)$ surface. Surf. Sci. 1991, 253, 245-257. [CrossRef]

23. Cao, G.; Moula, M.G.; Ohno, Y.; Matsushima, T. Dynamics on Individual Reaction Sites in Steady-State Carbon Monoxide Oxidation on Stepped Platinum(113). J. Phys. Chem. B 1999, 103, 3235-3241. [CrossRef]

24. Rzeźnicka, I.; Goula Moula, M.; Morales de la Garza, L.; Ohno, Y.; Matsushima, T. $\mathrm{CO}_{2}$ desorption dynamics on specified sites and surface phase transitions of $\mathrm{Pt}(110)$ in steady-state CO oxidation. J. Chem. Phys. 2003, 119, 9829-9841. [CrossRef]

25. King, D.A.; Wells, M.G. Molecular beam investigation of adsorption kinetics on bulk metal targets: Nitrogen on tungsten. Surf. Sci. 1972, 29, 454-482. [CrossRef]

26. Bowker, M. The molecular beam reactor. Appl. Catal. A Gen. 1997, 160, 89-98. [CrossRef]

27. Liu, J.; Xu, M.; Nordmeyer, T.; Zaera, F. Sticking Probabilities for CO Adsorption on Pt(111) Surfaces Revisited. J. Phys. Chem. 1995, 99, 6167-6175. [CrossRef]

28. Jiang, L.Q.; Koel, B.E. Hydrocarbon trapping and condensation on platinum (111). J. Phys. Chem. 1992, 96, 8694-8697. [CrossRef]

29. Speller, S.; Kuntze, J.; Rauch, T.; Bömermann, J.; Huck, M.; Aschoff, M.; Heiland, W. The $(1 \times 2)$ and $(1 \times 4)$ structure on clean Pt(110) studied by STM, AES and LEED. Surf. Sci. 1996, 366, 251-259. [CrossRef]

30. Helveg, S.; Lorensen, H.T.; Horch, S.; Lægsgaard, E.; Stensgaard, I.; Jacobsen, K.W.; Nørskov, J.K.; Besenbacher, F. Oxygen adsorption on $\mathrm{Pt}(110)-(1 \times 2)$ : New high-coverage structures. Surf. Sci. 1999, 430, L533-L539. [CrossRef]

31. Nettesheim, S.; Von Oertzen, A.; Rotermund, H.H.; Ertl, G. Reaction diffusion patterns in the catalytic CO-oxidation on Pt(110): Front propagation and spiral waves. J. Chem. Phys. 1993, 98, 9977-9985. [CrossRef]

32. Bowker, M. The 2007 Nobel Prize in Chemistry for Surface Chemistry: Understanding Nanoscale Phenomena at Surfaces. ACS Nano 2007, 1, 253-257. [CrossRef] [PubMed] 
33. Mullins, C.B.; Rettner, C.T.; Auerbach, D.J. Dynamics of the oxidation of CO on Pt(111) by an atomic oxygen beam. J. Chem. Phys. 1991, 95, 8649-8651. [CrossRef]

34. Butcher, D.R.; Grass, M.E.; Zeng, Z.; Aksoy, F.; Bluhm, H.; Li, W.X.; Mun, B.S.; Somorjai, G.A.; Liu, Z. In Situ Oxidation Study of Pt(110) and Its Interaction with CO. J. Am. Chem. Soc. 2011, 133, 20319-20325. [CrossRef]

35. Da Silva, J.L.K.; Stampfl, C. Trends in adsorption of noble gases He, Ne, Ar, Kr, and Xe on Pd(111). Phys. Rev. B 2008, 77, 045401. [CrossRef]

36. Redhead, P.A. Thermal desorption of gases. Vacuum 1962, 12, 203-211. [CrossRef]

37. Comrie, C.M.; Lambert, R.M. Chemisorption and surface structural chemistry of carbon monoxide on $\mathrm{Pt}(110)$. J. Chem. Soc. Faraday Trans. 1 Phys. Chem. Condens. Phases 1976, 72, 1659-1669. [CrossRef]

38. Bonzel, H.P.; Ku, R. Adsorbate interactions on a Pt(110) surface. I. Sulfur and carbon monoxide. J. Chem. Phys. 1973, 58, 4617-4624.

39. Fair, J.; Madix, R.J. Low and high coverage determinations of the rate of carbon monoxide adsorption and desorption from Pt(110). J. Chem. Phys. 1980, 73, 3480-3485. [CrossRef]

40. Jones, I.Z.; Bennett, R.A.; Bowker, M. CO oxidation on Pd(110): A high-resolution XPS and molecular beam study. Surf. Sci. 1999, 439, 235-248. [CrossRef]

41. Kisliuk, P. The sticking probabilities of gases chemisorbed on the surfaces of solids. J. Phys. Chem. Solids 1957, 3, 95-101. [CrossRef]

42. Ohno, Y.; Sanchez, J.R.; Lesar, A.; Yamanaka, T.; Matsushima, T. Angular distribution of desorbing carbon dioxide produced in two processes on a stepped platinum (557) surface. Surf. Sci. 1997, 382, 221-230. [CrossRef]

Publisher's Note: MDPI stays neutral with regard to jurisdictional claims in published maps and institutional affiliations. 